Este artículo presenta una tipología de malapropismos y otros DOSSIER $\cdot 71-82$ lapsus léxicos basada en los casos encontrados en el original inglés de la obra de Shakespeare Mucho ruido y pocas nueces, junto a las soluciones aportadas por cinco traductores al español de ejemplos de los seis tipos catalogados. Al basarse esta tipología principalmente en la evocación de un término in absentia por medio de su relación paronímica con otra palabra erróneamente emitida, el traductor puede aplicar a este caso específico una amplia gama de estrategias recogidas en el análisis descriptivo, siempre con la conciencia auditiva de la descodificación inmediata requerida por el espectador teatral. La base epistemológica incluye referencias a las máximas conversacionales de Grice, a la teoría de la relevancia de Sperber y Wilson y la aplicación de esta última a la traducción por parte de Gutt.

PaLABRAS ClaVE: Traducción, teatro, relevancia, Shakespeare, malapropismo, paronimia.

\title{
Hacia una tipología del malapropismo shakespeareano y sus estrategias de traducción
}

JOHn D. SANDERSON

Universidad de Alicante
This paper presents a typology of malapropisms and other lexical lapses based on the cases found in Shakespeare's play Much Ado About Nothing and the solutions given by five different Spanish translators to examples of the six types that have been classified. Since this typology is commonly based on the evocation of a word in absentia by means of the paronymical relationship with another word which has mistakenly been uttered, the theatre translator can make use, for this specific task, of the wide range of strategies recorded in the descriptive analysis, being aware of the requirements of immediate aural decoding by an audience. A theoretical basis is supplied with references to Grice's conversational maxims, Sperber and Wilson's theory of relevance and its application to translation by Gutt.

KEYWORDS: Translation, theatre, relevance, Shakespeare, malapropism, paronymy. 
The translator is a dramaturg who must first of all effect a macrotextual translation, that is, a dramaturgical analysis of the fiction conveyed by the text.

Pavis (I989:27)

Este análisis macrotextual previo que Pavis recomendaba tan encarecidamente se contraponía a la traducción línea por línea desde principio a final de una obra de teatro solventando los problemas traductores conforme se fueran presentando. Con este planteamiento anticipatorio sobre la globalidad del texto cabrían, entonces, otro tipo de consideraciones literarias, lingüísticas, y, lógicamente, traductológicas, pero siempre obtenidas desde esta perspectiva macrotextual sobre la obra antes de que se empezara a traducirla. Y uno de los aspectos más importantes en este sentido es el tratamiento individualizado de la totalidad de las intervenciones de cada personaje para que haya una coherencia en las decisiones traductoras con vistas a su caracterización en el nuevo contexto cultural ya que, a diferencia de una novela, aquí se carece de otra fuente informativa, como puede ser una voz narrativa, que nos aporte datos adicionales sobre su personalidad o actitud. Apenas hay unas didascalias que suelen referirse en mayor medida a la actividad física que a la evolución psicológica del personaje. E1 diálogo será, por tanto, determinante.

En este artículo nos vamos a ceñir a una tipología de personaje, el alguacil torpe representado por Dogberry en Much Ado About Nothing (Mucho ruido y pocas nueces, 1598), que ya contaba con una cierta tradición cultural isabelina cuando Shakespeare lo incorporó a su obra, para analizar un rasgo distintivo verbal por el que es reconocible en sus intervenciones: la frecuencia con la que incurre en errores léxicos cuando intenta evocar términos oídos a miembros de clases sociales más elevadas. Al no estar habituado el personaje a este registro, se equivoca utilizando otras lexías fónicamente similares pero semánticamente alejadas, en muchos casos incluso antónimas. La reiteración de este lapsus léxico, llamado en líneas generales malapropismo, será un recurso humorístico que servirá para caracterizarle y para provocar la hilaridad del espectador, quien deducirá el término que pretendía utilizar a partir de la lexía errónea producida.

Este último aspecto plantea un reto inusual para el traductor teatral, ya que deberá dirimir si su atención se orienta hacia el término presente en el texto original, hacia el término subyacente no expresado, o hacia ambos en mayor o menor medida, si quiere producir en el receptor meta un efecto ilocutivo equivalente al hipotéticamente producido en el contexto origen. Además de esto, si tenemos en cuenta la inmediatez del hecho teatral, resultará aplicable la advertencia de Gutt (I99I: II6): «Since the stream of speech flows on, the audience cannot be expected to sit and ponder difficult renderings - otherwise it will lose the subsequent utterance; hence it needs to be able to recover the intended meaning instantly». El término elegido por el traductor deberá, por tanto, evocar con facilidad para el espectador el pretendido pero no emitido para mantener activa su participación en la recepción auditiva del texto ya que, de nuevo, a diferencia de la novela, en una sala teatral no podemos hacer uso de recursos paratextuales para glosar el recurso transferido al nuevo contexto.

El propósito de este artículo consiste en desarrollar una tipología de lapsus léxico a partir de los numerosos ejemplos que se pueden encontrar en Much Ado About Nothing, para realizar a continuación un análisis descriptivo de las soluciones aportadas en un corpus de 
cinco traducciones al español de cada uno de los ejemplos representativos de cada caso. Esto nos permitirá también desarrollar un abanico de estrategias traductoras en las que se requiere una descodificación fónica apropiada ya que, en el texto origen, el comúnmente llamado malapropismo se produce en la mayoría de los casos por la similitud formal entre dos términos semánticamente distintos. Como afirma Ricks (I990: 464): «All jokes depend on stereotypes, upon generalizations, and upon typicalities or representativeness which can easily - as we now easily know - constitute an abuse as well as be abusive.» Se explicaría entonces la presencia mayoritaria de malapropismos al inicio de la primera escena en la que interviene Dogberry (III.iii) al interés dramatúrgico por caracterizar al personaje. La reiteración percibida en el texto origen requeriría una traslación equivalente al texto meta, ya que, en este caso, el error contribuye a establecer el arquetipo en esta y otras obras.

En su artículo «Verbal evocation», el lexicólogo Bolinger (I96r: II3) da una definición coloquial del lapsus léxico: «Crudely stated, this has to do with a sign whose meaning is known but whose verbal form has been forgotten.» El análisis de este fenómeno se basará en el reconocimiento de una ausencia léxica y del mecanismo de asociación mental por el cual se ha producido una sustitución errónea por parte del emisor con el objetivo de dar continuidad a su discurso. Los campos de asociación mental son diversos, y en muchos casos se superponen, pero Aitchison (I987: 9-18) se basa en la premisa de que «anyone who accidentally produces a wrong word is likely to have picked one closely related to the intended word or 'target'» para dividir estos campos de asociación en tres grandes grupos: asociación por sonido, asociación por significado, y una interrelación entre ambos.
En el campo de la ficción argumental, la intención del autor sería que fuera el receptor del texto, más que el interlocutor en la obra de quien incurre en el error, el que lograra mantener la continuidad del discurso identificando el término no emitido. La percepción de dicho lapsus léxico implicará entonces la evocación de la lexía in absentia, que depende tanto de su relación con la lexía in praesentia como del contexto lingüístico inmediato en el que se produce. La recurrencia en dicho error por parte de un personaje concreto del texto contribuirá a generar unas expectativas que progresivamente facilitarán esa identificación y, paralelamente, aumentarán el deseo participativo del receptor. En el caso del alguacil Dogberry y sus ayudantes, será el malapropismo en el que incurren repetidamente el que determine su funcionalidad como personajes, el de contrapunto cómico en las cuatro escenas en las que aparecen con respecto al dramatismo generado por el desencuentro amoroso entre los jóvenes Claudio y Hero, con todas las ramificaciones sociales que comportan para Messina, ciudad italiana donde se desarrolla la obra.

El término malapropismo (calco léxico del inglés malapropism) se acuña a partir de una obra del dramaturgo irlandés Richard Brinsley Sheridan: The Rivals (I775). En dicho texto hay un personaje, la señora Malaprop, que retiene en su mente vagos recuerdos de palabras oídas a personas de clase social elevada, y en su afán por aparentar distinción se propone reutilizarlas, confundiéndolas con otras en base a su similitud formal. Curiosamente, dicho término se ha empleado con regularidad para analizar $M u c h$ Ado About Nothing, una obra escrita con casi dos siglos de anterioridad, lo cual podría confirmar la máxima de Bloom (I994: Io): "Coming after Shakespeare, who wrote both the best prose and the best poetry in the Western Tradition,

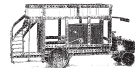


is a complex destiny, since originality becomes peculiarly difficult». De hecho, el malapropismo más popular de esta obra (cuya traducción analizaremos con posterioridad) está basado en una evocación del conocido proverbio «Comparisons are odious», que en boca de Dogberry se transforma en "Comparisons are odorous», y por parte de la señora Malaprop en un más elaborado "Caparisons are odorous»; eso sí, ciento ochenta años después.

Como se puede comprobar, los términos erróneos guardan una relación paronímica con los pretendidos, lo cual concuerda con la afirmación de Aitchinson (1987: 126) en este sentido: «In general, then, words which have similar beginnings, similar endings and similar rhythm are likely to be tightly bonded.» Esta percepción coincide con la casuística de la obra objeto de análisis en este artículo, donde se localizan una treintena de malapropismos que se pueden dividir inicialmente en cuatro grupos que se caracterizan por:

a) el mantenimiento de la secuencia fonémica inicial común;

b) el mantenimiento de la secuencia fonémica final común;

c) el mantenimiento de las secuencias inicial y final comunes, con la modificación de la secuencia fonémica medial;

d) la incorporación o la omisión de una secuencia fonémica en el término pretendido.

Sin embargo, se cometen otros errores terminológicos por parte de este personaje arquetípico que no se considerarían propiamente malapropismos al no apreciarse similitud formal, pero que, sin embargo, desarrollan el mismo proceso, ya que se produce una lexía errónea que permite al receptor del texto descodificar el término pretendido. La confusión se genera en estos casos por la carga semántica adscrita

erróneamente al término utilizado.

e) Asociación léxica por antonimia: la lexía emitida es semánticamente opuesta a la pretendida.

f) Asociación léxica por homonimia: la carga semántica adscrita a la palabra homónima no es la que corresponde al contexto conversacional.

La incorporación de esta casuística confirmaría la investigación de Aitchison mencionada arriba en el sentido de que la asociación léxica también se produciría por significado, y no exclusivamente por sonido. En estos dos últimos apartados, por tanto, al no haberse establecido una vinculación fónica, toda la información que se posea sobre la situación conversacional será la que posibilitará la evocación del término ausente. De hecho Dascal (I98r: 154) define más específicamente como cotexto: «the linguistic environment of an utterance», al conjunto de términos inmediatamente adyacentes que contribuyen a descodificar el término opaco u erróneo, un concepto que puede resultar útil al desarrollar esta tipología de lapsus léxico. E1 traductor deberá tener en cuenta que el receptor descarta la carga semántica de la lexía presente en la estructura superficial precisamente gracias a la información co/contextual.

Para analizar la cooperación requerida por parte del receptor nos referiremos a la teoría de la relevancia de Sperber y Wilson (I986), que fundamenta su investigación precisamente en el principio de cooperación conversacional de Grice (I975). La descodificación de un enunciado dependerá en buena medida de la voluntad de un interlocutor que sólo estaría dispuesto a realizar un esfuerzo interpretativo si espera obtener beneficios contextuales del mismo. El emisor procurará, por tanto, incluir los suficientes elementos reconocibles para dejar explícito su propio contexto comunicativo y hacer par- 
tícipe del mismo al receptor. Según Sperber y Wilson (1986: 50), esta explicitación se manifestaría por medio de un «ostensive behaviour», ya que «an act of ostension carries a guarantee of relevance, and that this fact - which we will call the principle of relevance - makes manifest the intention behind the ostension». En el hecho teatral, el "comportamiento ostentoso» del cómico es una característica referencial de su funcionalidad en la globalidad de la representación, y así se activaría la predisposición del espectador a cooperar ante la expectativa de obtener un beneficio en forma de efecto humorístico.

Ezpeleta (2007: 352) hace una muy completa aplicación de la teoría de la relevancia a la traducción teatral y alude al lapsus léxico que nos ocupa en este artículo: «Son especialmente representativos los malapropismos como indicadores de falta de formación o de poca capacidad de los personajes; pero su relevancia está relacionada, también, con aspectos sociales, ya que indican los intentos de un personaje por superar los hábitos lingüísticos de la clase social a la que pertenece y su incapacidad para conseguirlo.» El aliciente del receptor iría, por tanto, en aumento al entroncarse este planteamiento con la teoría de la superioridad vinculada al humor, cuyo origen se remonta a La república de Platón, y de la que podemos encontrar referencias recientes en Attardo (200I). El receptor que descodificara la lexía pretendida pero no emitida en Much Ado About Notbing con motivo del lapsus léxico celebraría así mismo su propia habilidad contrastada con la incapacidad de Dogberry para expresarse correctamente. Se generaría, por tanto, un sentimiento de superioridad sobre el personaje del que uno se ríe, lo cual contribuiría a que el público participara en sus sucesivas apariciones.

Evidentemente, al traductor también se le requerirá un esfuerzo mayor. Como consecuencia de la asimetría interlingüística, difícilmente se puede esperar que en el código meta coincida la relación paronímica entre los dos términos semánticamente distantes que constituyen el malapropismo en el texto origen. El proceso traductor habría de empezar, por tanto, por la adecuada identificación del lapsus léxico original antes de emprender la búsqueda de un equivalente en el nuevo contexto. Como afirma Mateo (1996: 912): «el traductor debe apreciar las características fonéticas de los sonidos empleados por el autor; no se trata sólo de palabras con contenido semántico, sino que a menudo la forma fónica de las mismas resulta significativa». Una vez localizados todos los malapropismos del texto origen y determinada su casuística, la adopción de una determinada estrategia traductora dará como resultado una mayor o menor caracterización del personaje dependiendo de la recurrencia de este tipo de lapsus en el texto meta.

Offord (1990: 199) realiza un estudio sobre la traducción del malapropismo shakespeareano al francés de la que obtiene una catalogación de seis estrategias traductoras que no por obvias dejan de ser útiles:

- no tener en cuenta el juego de palabras;

- imitar la técnica de Shakespeare;

- priorizar el significado superficial;

- priorizar el significado subyacente;

- incluir los dos significados (sin producir un juego de palabras);

- crear un juego de palabras distinto.

La aplicación de una u otra estrategia dependería, en todo caso, primeramente en la identificación del malapropismo y a continuación en la mayor o menor facilidad para trasladarlo al texto meta. De hecho, en un artículo posterior que incluía un análisis descriptivo de la traducción de juegos de palabras shakespeareanos 
al francés divididos en horizontales (cuando aparecen los dos términos) y verticales (cuando sólo aparece uno), Offord (1997: 256) llega a la 76 conclusión de que, con el primer tipo, la opción mayoritaria es crear un nuevo juego de palabras (33\% de los casos), mientras que con el segundo principalmente se prioriza el significado superficial (45\%). Este último dato le permitía llegar a la conclusión de que en un número significativo de casos no se habría identificado el juego de palabras en el texto origen.

A continuación vamos a ejemplificar la casuística de lapsus léxico arriba indicada con seis ejemplos extraídos de Much Ado About Nothing (uno por cada caso) y la solución traductora aportada en cinco versiones españolas del texto que nos permitirán observar la variedad de estrategias traductoras aplicadas.

\section{MALAPROPISMO CON MANTENIMIENTO DE LA SECUENCIA FONÉMICA INICIAL}

DOGBERry You are thought here to be the most senseless and fit man for the constable of the watch.

(III.iii.22-3)

En su primera aparición en la obra, el alguacil Dogberry escoge a quienes harán guardia en Messina esa noche. Ante la presuposición de que pretende escoger a los más válidos (impresión reforzada por la utilización del adjetivo fit), el receptor deduce que ha cometido un error léxico al aludir a una característica negativa, senseless. Por similitud formal se inferiría que la lexía subyacente es sensible (sensato) y el malapropismo se habrá producido mediante el mantenimiento del lexema sens(e) y la sustitución del sufijo -ible por -less, el cual conlleva una carga semántica antónima a la pretendida.
NAVARRA, I868 Se os considera el hombre más sensato y digno del mando de la ronda.

CLARK, I87I Pasáis aquí por el hombre más insensato y el más a propósito para ser jefe de esta ronda

ASTRANA, I929 Pasáis aquí por el hombre más insensato y el más a propósito para alguacil de la ronda.

VARELA, I946 Pasáis aquí por ser el hombre menos sensato y el más capacitado para actuar como jefe de la guardia

VALVERDE, I967 Aquí se piensa que eres el hombre más apropiado y más insensato para ser cabo de la ronda

Podemos apreciar como la tendencia traductora mayoritaria (tres de los cinco casos) consiste en añadir el prefijo in- a la hipotética lexía pretendida para producir un término antónimo, una modificación fonémica menor que la producida al añadir el adverbio menos. Se debe destacar la opción de Valverde que, al invertir el orden de los términos, favorecería la contextualización del término $\mathrm{y}$, consiguientemente, la percepción de que se ha incurrido en un malapropismo ante el contraste con el término anterior.

\section{MALAPROPISMO CON MANTENIMIENTO DE LA SECUENCIA FONÉMICA FINAL}

DOGBERRY Dost thou not suspect my place? Dost thou not suspect my years?

$$
\text { (IV.ii.7I-2) }
$$

El alguacil Dogberry recrimina a dos malhechores que no le guarden el respeto debido que hipotéticamente le correspondería por su cargo. El malapropismo se constituye por el mantenimiento de la secuencia fonémica final - ect, y la sustitución de la secuencia fonémica inicial resp- por susp-, dando como resultado una lexía con una carga semántica opuesta. 
Se trata de la tipología de malapropismo más recurrente en la obra. Hemos elegido un caso que se origina a partir de un lexema, respect, que resultaría más meritorio que el mantenimiento de los sufijos habituales. Aitchinson (I987: II4) considera que la "preservation of the end of the word occurs more often in suffixed words than in those without a suffix». Shakespeare los utiliza, como en «suffer salvation» (III.iii.3) para evocar "suffer damnation», pero su maestría le conduce hacia la tipología que ilustra este apartado, u otros como «comprehend» (III.iii.25 y v.43) para evocar «apprehend».

NAVARRA, I868 ¿No te impone respeto mi cargo? $¿$ ¿Tampoco respetas mi edad?

CLARK, I87I ¿No te difunde respeto mi cargo? $¿$ No te difunden respeto mis canas?

ASTRANA, I929 ¿No te infunde sospecha mi cargo? $¿$ No te infunde sospecha mi edad?

VARELA, I946 ¿Es que no sospechas mi cargo? $¿$ ¿No sospechas mi edad?

VALVERDE, I967 ¿Sin respecto para mi cargo, sin respecto para mis canas?

En dos de los cinco casos (Clark y Astrana) observamos como, a partir de la colocación, «infundir respeto», se lleva a cabo la sustitución de uno de los términos. Astrana incorpora las dos cargas semánticas del texto origen, pero no resulta fónicamente verosímil la utilización de «sospecha» en lugar de «respeto». Por otra parte, Clark sustituye «infunde» por «difunde», que sólo se diferencian por la secuencia fonémica inicial, lo cual establece una relación paronímica muy válida, pero la modificación semántica no es tan sustancial como en el original. Aplicando la misma estrategia, la utilización de «confunde» quizás habría sido más efectiva.

Valverde produce la menor modificación fonética (un solo fonema), sin una modificación semántica relevante, mientras que Varela prio- riza la lexía superficial y Navarra, como en el ejemplo anterior, no parece identificar el lapsus léxico.

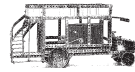

\section{MALAPROPISMO CON MODIFICACIÓN DE LA} SECUENCIA FONÉMICA MEDIAL

DOGBERRY Comparisons are odorous.

(III.v.I5)

Dogberry incurre en este célebre malapropismo cuando se vanagloria de sus aptitudes en comparación con las de sus ayudantes. El malapropismo se compone mediante el mantenimiento de las secuencias fonémicas inicial y final, sustituyéndose el fonema intermedio /i/ por la secuencia fonémica /or/.

NAVARRA, I868 Las comparaciones son olorosas.

CLARK, I87I Las comparaciones son olorosas.

ASTRANA, I929 Las comparaciones son olorosas.

VARELA, I946 Las comparaciones son olorosas.

VALVERDE, I967 Las comparaciones son ociosas.

La tendencia mayoritaria (tres de los cinco casos) ha sido la de trasladar literalmente la lexía producida, odorous, al código meta con el término «olorosas». En otro caso observamos un acuñamiento ad hoc, «odorosa», fónicamente similar al del texto origen. Y por último, la opción de Valverde es de nuevo la que menor modificación fonética produce, ya que solamente se modifica un fonema, $/ \theta /$ en lugar $\mathrm{de} / \mathrm{d} /$.

En un estudio sobre la traducción del malapropismo shakespeareano realizado por Soto Vázquez (2000: Io) y publicado en la revista que él mismo dirigía, Insights into Translation, analizaba algunos ejemplos utilizando las traducciones de Navarra, Astrana y Valverde, y en este caso concreto considera que "José María Valverde accomplishes the effect but not the 
meaning; Luis Astrana Marín and Jaime Navarra Farré achieve both effect and meaning». Sin embargo, se podría argumentar que, al ser un malapropismo elaborado a partir de una similitud formal que tendría mayor relevancia que su carga semántica, la opción de Valverde sería más efectiva en ese sentido al ser más verosímil la menor modificación fonética. En otras palabras, cuanto más próximas sean las palabras paronímicamente hablando, menor será el esfuerzo descodificador requerido y más creíble el error en el que se ha incurrido, además de que se garantizaría en mayor medida la producción de un efecto ilocutivo humorístico.

\section{MALAPROPISMO POR INCLUSIÓN DE SECUENCIA FONÉMICA}

Dogberry Come, let them be opinioned.

(IV.ii.64)

Dogberry ordena a sus guardias que aten a los malhechores, pero al querer utilizar un término de registro elevado se equivoca en la elección al añadir el fonema /o/ al lexema pinion («maniatar»), transformándolo en opinion (inusualmente utilizado aquí como verbo).

NAVARRA, I868 Andando, vamos a ver lo que se hace de vosotros.

CLARK, I87I Vamos, manoseadlos.

ASTRANA, I929 ¡Vamos, que se obstinan!

VARELA, I946 Que los maniaten.

vALVERDE, I967 Vamos, a llevarles desposados.

En sólo dos de los cinco casos parece haberse identificado la existencia de un malapropismo. Clark opta por la estrategia definida en el apartado anterior con referencia al texto origen. Lo elaborara a partir del mantenimiento del lexema inicial man- y de la secuencia fonémica final -adlos para utilizar «manoseadlos» como evocador de «maniatadlos», produciendo un evidente efecto ilocutivo humorístico. Valverde de nuevo elabora el malapropismo con la menor modificación fonética (sólo le incorpora el fonema inicial /d/ a «esposados») aportando una modificación de la carga semántica muy efectiva. Ambos ejemplos podrían considerarse traducciones que, pese a no haberse ceñido a las cargas semánticas del original, al priorizar la vinculación paronímica producen unos resultados, como mínimo, tan efectivo como el del texto origen.

\section{ASOCIACIÓN LÉXICA POR ANTONIMIA}

SECOND WATCH Let us obey you to go with us.

(III.iii.I69-I70)

Pese a que se dan siete casos de esta tipología de lapsus léxico, la mayoría adscritos a Dogberry, he creído oportuno utilizar como ejemplo este segmento en el que uno de los miembros de la guardia intenta emular a su superior en la utilización de un registro más elevado. E1 cotexto ya creado en esta primera escena de la obra en la que aparece el alguacil predispondría al espectador a descodificar, en una estructuración dramática in crescendo, este tipo de errores por parte de cualquiera de sus subalternos. En este caso concreto, cuando uno de los guardias bajo el mando de Dogberry ordena a los malhechores detenidos que le sigan, utiliza una lexía antónima, obey, que no guarda similitud formal con la pretendida, order, pero cuyo cotexto permite descodificar.

NAVARRA, I868 Os ordenamos que vengáis con nosotros.

CLARK, I87I Os queremos obedecer llevándoos con nosotros. 
ASTRANA, 1929 Os intimidamos a que os dejéis obedecer, y nos sigáis.

VARELA, I946 Os conjuramos a que no dejéis de obedecernos y vengáis con nosotros.

VALVERDE, I967 Obedecednos y venid con nosotros.

En sólo dos de los casos parece haberse identificado el lapsus léxico, ya que las propuestas de Navarra, Varela y Valverde no aportan ninguna contradicción semántica. Clark y Astrana sí priorizan la lexía producida expresando la carga semántica antónima, aunque en el segundo caso la longitud del enunciado pueda perjudicar la evocación de la lexía pretendida. Teniendo en cuenta, como afirmaba Corrigan (I96r: ro6) con respecto a la representación teatral del texto traducido, que «the duration per se of a stage utterance is part of its meaning», la simplificación aportada por Clark sería la más efectiva, o incluso un enunciado más escueto como «iOs obedecemos que nos sigáis!», donde el cotexto inmediato permitiría descodificar el término in absentia.

\section{ASOCIACIÓN LÉXICA POR HOMONIMIA}

SECOND WATCH: I know him, a wears a lock.

\section{$[\ldots]$}

(III.iii.I63-4)

DOGBERRY They say he wears a key in his ear, and a lock hanging by it,

$$
\text { (v.i.3O2-3) }
$$

Es el único caso en todo el texto de esta tipología de lapsus léxico, pero constituye el momento culminante de la participación de Dogberry en la obra, al final de la primera escena del quinto acto, la última que cuenta con su presencia, por lo que considero relevante su análisis. Además, es una demostración práctica de la conveniencia del planteamiento macrotextual sugerido por Pavis, tal y como se recoge al principio de este artículo, ya que el error terminológico del alguacil se origina a partir de un enunciado que se encuentra en el tercer acto, cuando el miembro de la guardia citado en el apartado anterior identifica a un sospechoso porque tiene un rizo. La interpretación errónea por parte de Dogberry de la carga semántica de lock (él la interpreta como «candado»), desencadena su incorporación de la lexía key («llave»).

NAVARRA, I868

-Yo le conozco; va con unos rizos.

-Dicen que lleva una llave en la oreja y un rizo colgado de ella,

CLARK, I87I

-Le conozco: lleva un rizo.

$-[\ldots]$ una llave en la oreja y colgado de ella un rizo.

ASTRANA, I929

- Le conozco; lleva un rizo.

-Dice que lleva una llave en la oreja y colgado de ella un rizo

VARELA, I946

-Yo le conozco; lleva un rizo en la cabellera.

-Dicen que lleva una llave en la oreja, con un rizo colgando

VALVERDE, I967

-Le conozco, tiene pelo ensortijado.

-Dicen que tiene el pelo con sortijas y anillos en las orejas,

Como se puede observar, únicamente Valverde parece haber percibido el lapsus léxico, ya que en el resto de los casos, al sólo haberse tenido en cuenta una de las acepciones del término lock no es posible inferir qué motiva al alguacil Dogberry a hacer alusión a una «llave». Valverde sí aporta una solución traductora mediante la utilización inicial de una metáfora fosilizada (el adjetivo derivado «ensortijado»), de la que extrae el lexema para dotarlo de su valor semántico original. Su elección conlleva la lógica desaparición de la referencia a la «llave» pero, en cualquier caso, produce un lapsus léxico en 
el clímax de su intervención que se consideraría esencial antes de que desaparezca.

Una alternativa culminante podría haberse 80 conseguido mediante la sustitución de la lexía «rizo» por «tirabuzón», para así aprovechar que una falsa etimología indujera a considerar este segundo término como una palabra compuesta de «tira» y «buzón», cuando en realidad es un galicismo (tire-bouchon). Se habría podido inferir entonces que la alusión a una «llave» se produjera por relación semántica con «buzón». La única objeción provendría del hecho de que los buzones no existieran como tales en el siglo XVI, pero el anacronismo de esta referencia podría no ser tan evidente como para producir el rechazo del espectador. Sería, en cualquier caso, una alternativa debatible, siempre teniendo en cuenta que, en la ardua labor del traductor, como afirma Díaz-Cintas (2003: 253): «El humor es, sin duda, uno de los ejemplos de recreación lingüística que más pone a prueba las habilidades del traductor, empujándole a extremos que le obligan a activar soluciones imaginativas que, en ocasiones, se han de alejar forzosamente del contenido del original si se quiere alcanzar un efecto similar».

\section{CONCLUSIONES}

La detección de un recurso estilístico iterativo por parte de un traductor contribuye a aportar una mayor coherencia macrotextual. Tratándose de una obra de teatro, puede incluso tener mayor importancia, ya que esa recurrencia en las intervenciones de un determinado personaje pueden ser determinantes a la hora de caracterizarlo con el objetivo de la puesta en escena. $\mathrm{Y}$ dentro de una representación, la buena definición del léxico elegido aportará unas claves fónicas relevantes para la recepción inmediata por parte del espectador. La labor del traductor implicará, por tanto, la traslación de estos elementos recurrentes al texto meta para que sea posible la descodificación de los enunciados, tanto de su contenido explícito como de las inferencias subsiguientes obtenidas por dichas repeticiones.

En este artículo se ha hecho alusión a la teoría de la relevancia desarrollada por Sperber y Wilson para destacar el ostentive gesture del emisor como garante de una voluntad comunicativa. El receptor que la percibe sería alentado, por tanto, a iniciar un proceso descodificador gracias a las expectativas creadas de que se podría producir un efecto humorístico, generándose la cooperación conversacional a la que aludía Grice. El personaje analizado, el alguacil Dogberry de Much Ado about Nothing, pertenece a un arquetipo del teatro isabelino que ha perdurado en el contexto origen con posterioridad, por lo que su identificación podría ser más sencilla para el espectador inglés. En cualquier caso, los recurrentes malapropismos en los que Shakespeare le hace incurrir constituyen un cotexto (Dascal, I98I) que posibilita la descodificación y asimilación de esta tipología de personaje por parte de receptores de otros contextos culturales distintos, siempre y cuando los lapsus léxicos hayan sido trasladados con una frecuencia similar al texto meta.

Soto Vázquez (2000: I4) concluye su artículo sobre la traducción del malapropismo shakespeareano afirmando que «it is very easy to find a great deal of equivalent malapropisms reflecting the comic effect of the original text, thus the lack of this literary device in the Spanish translation is unforgivable». Sin embargo, como se ha podido comprobar en el análisis descriptivo, se trata de una labor compleja, motivada principalmente por el anisomorfismo interlingüístico tanto en relaciones paronímicas como homoní- 
micas entre palabras. El objetivo de este artículo ha sido únicamente desarrollar una tipología de lapsus léxico o malapropismo aportando un único ejemplo de cada uno de los casos y las soluciones aportadas en cinco traducciones al español.

Basándonos en los segmentos traducidos aquí presentados, la tendencia mayoritaria coincide con la observada por Offord en la traducción al francés de los juegos de palabras en los que sólo aparece una de las acepciones: la atención traductora se decanta por la utilización de un término que guarde una relación semántica y formal con la lexía in praesentia en I9 de los 30 casos. También hay que destacar que la variedad de estrategias traductoras aplicadas distintas del recurso original no afectarían negativamente a la producción del efecto ilocutivo humorístico hipotéticamente buscado.

Siempre teniendo en cuenta que, tratándose de un texto teatral, la posibilidad de su puesta en escena implicaría una mayor sensibilidad fónica por parte del traductor, habría que destacar los segmentos procedentes de la versión de José María Valverde, donde se observa una mayor relación paronímica entre los términos in praesentia e in absentia pese a su alejamiento semántico del original en comparación con otras traducciones. Para alentar y favorecer la participación descodificadora del espectador ante la inmediatez del hecho teatral, en el caso del malapropismo se podría llegar a la conclusión de que, a menor desviación fonémica y mayor desviación semántica entre las dos lexías en el texto meta, más efectivo será el acto ilocutivo humorístico, ya que la lexía pretendida se evocará con mayor facilidad a partir de la lexía producida. Y en este sentido se observa en los segmentos de Valverde una prioridad por el efecto fónico.

En suma, cuando la similitud formal entre los dos términos del texto origen no se puede mantener en el código meta por motivos de asimetría interlingüística, se llegaría a la conclusión de que parecería preferible manipular la traducción a partir de la lexía pretendida pero no emitida hasta encontrar un término vinculable, fónica y/o semánticamente, en la estructura superficial que permitiera su identificación. Con el establecimiento de una tipología de malapropismos y un análisis descriptivo de las distintas traducciones existentes se contribuye a que se puedan barajar diversas estrategias traductoras para establecer puentes entre la lexía in absentia y la lexía in praesentia, y así alentar al receptor, en último caso el espectador teatral, para que prosiga con su esfuerzo descodificador en pos del beneficio contextual que le espera en forma de diversión. Las comedias de Shakespeare ya han demostrado repetidamente su efectividad en ese sentido.

RECIBIDO EN DICEMBRE 2008

ACEPTADO EN FEBRERO 2009

\section{REFERENCIAS BIBLIOGRÁFICAS}

Aitchison, J. (1987). Words in the Mind. An Introduction to the Mental Lexicon, Oxford: Blackwell.

Arrowsmith, W y Shattuck, R (eds.) (I96I). The Craft and Context of Translation, Austin: Texas U.P.

Attardo, S. (200I). Linguistic Theories of Humor, Berlín y Nueva York: Mouton de Gruyter.

Bloom, H. (1994). The Western Canon: The Books and School of the Ages, Londres: Macmillan.

Bolinger, D. L. (I96I). «Verbal Evocation». Lingua, IO, pp. II -27 .

Cole, P. y J. L. Morgan (eds.) (1975). Syntax and Semantics vol. 3: Speech Acts, Nueva York: Academic Press.

Corrigan, R. W. (I96I). «Translating for Actors», en W. Arrowsmith y R. Shattuck (eds.), pp. 95-106.

Dascal, M. (I98I). «Contextualism», en H. Parret, M. 
Sbisa y J. Verscoweren (eds.), pp. I53-I77.

Delabastita, D. (ed.) (1997). Traductio. Essays on Punning and Translation, Manchester: Saint Jerome.

Díaz-Cintas, J. (2003). Teoría y práctica de la subtitulación inglés-español, Barcelona: Ariel.

Ezpeleta Piorno, P. (2007). Teatro y traducción. Aproximación interdisciplinaria de la obra de shakespeare, Madrid: Cátedra.

Fawcett, P. y O. Heathcote (eds.) (I990). Translation in Performance: Papers on the Theory and Practice of Translation, Bradford: University of Bradford.

Follkart Di Stefano, B. (1982). «Translation as Literary Criticism». Meta 27/3, pp. 24I-256.

Gaddis Rose, M. (ed.) (1981). Translation Spectrum: Essays in Theory and Practice, Albany: State University of N. Y. Press.

Grice, H. P. (1975). «Logic and Conversation», en P. Cole y J. L. Morgan (eds.), pp. 44-58.

Gutt. E. A. (I99I). Translation and Relevance: Cognition and Context, Oxford: Blackwell. I993.

Mateo, M. (I996). «El componente escénico en la traducción teatral». Actes del I Congrés Internacional sobre Traducció, Universitat Autónoma Barcelona, Vol. II, Barcelona: Servei de Publicacions UAB, pp. 907-917.

Offord, M. (I990). «Translating Shakespeare's World Play», en P. Fawcett y O. Heathcote (eds.), pp. IOI-I4O.

- (r997). «Mapping Shakespeare's Puns in French Translations», en Delabastita, D. (ed.), pp. 233.260.

Parret, H., M. Sbisa y J. Verscoweren (eds.) (I98I). Possibilities and Limitations of Pragmatics, Amsterdam: John Benjamins.

Pavis, P. (I989). "Problems of Translation for the Stage: Interculturalism and Post-modern Theatre», en H. Scolnicov y P. Holland (eds.) The
Play out of Context: Transferring Plays from Culture to Culture, Cambridge: Cambridge University Press, pp. 25-44.

Platón (1992). Diálogos: República, tr. Conrado Eggers Lan, Madrid: Gredos.

Ricks, C. (I990). «Word Making and Mistaking», en C. Ricks y L. Michaels (eds.), pp. 46o-6.

Ricks, C. y L. Michaels (1990). The State of the Language, Londres: Faber \& Faber.

Shakespeare, William. (I598). Much Ado About Nothing [Mucho ruido y pocas nueces].

Humphreys, A. R. (ed.) (I98I). Londres y Nueva York: Arden.r994.

Navarra Farré, J. (trad.) (I868). Barcelona: Ediciones B. 1997.

Clark, J. (trad.) (I87I). Madrid: Medina y Navarro.

Astrana Marín, L. (trad.) (I929). Madrid: Aguilar. I98I.

Varela, R. (trad.) (1946). Barcelona: Iberia. I970.

Valverde, J. M. (trad.) (I967). Barcelona: Planeta.

Sheridan, R. B. (I775). The Rivals, E. Duthey (ed.), Londres: A. \& C. Black. r988.

Soto Vazquez, A. L. (2000). «Shakespeare's Use of Malapropisms in Much Ado About Notbing and their Reception in Spanish Translations». Insights into Translation, 2, A Coruña: Universidade da Coruña, pp. 7-I5.

Sperber, D. y D. Wilson (I986). Relevance: Communication and Cognition, Oxford: Blackwell.

Wellwarth, G. E. (I98I) «Special Considerations in Drama Translation», en M. Gaddis Rose (ed.), Translation Spectrum: Essays in Theory and Practice, Albany: State University of N. Y. Press, pp. I4O-I46. 